\title{
Effect of stir casting parameters on particle distribution, microstructure, and properties of metal matrix composite using alumina master alloy
}

\author{
Š. Nagy ${ }^{1 *}$, M. Nosko ${ }^{1}$, K. Iždinský ${ }^{1}$, V. Trembošováa ${ }^{1,2}$, T. Dvorák ${ }^{1}$ \\ ${ }^{1}$ Institute of Materials and Machine Mechanics SAS, Dúbravská cesta 9/6319, 84513 Bratislava, Slovak Republic \\ ${ }^{2}$ Institute of Materials Science, Faculty of Material Sciences and Technology in Trnava, \\ Slovak University of Technology in Bratislava, Jána Bottu 2781/25, 91724 Trnava, Slovak Republic
}

Received 23 August 2019, received in revised form 21 July 2020, accepted 25 September 2020

\begin{abstract}
In the present study, the different approach of metal reinforcement particles addition was studied. Aluminum matrix composite (AMC) with $5 \%$ alumina $\left(\alpha-\mathrm{Al}_{2} \mathrm{O}_{3}\right)$ reinforcement was prepared via stir casting method, using various casting temperature, stirring speed, and stirring time. As a source of reinforcement, alumina master alloy with a high concentration of alumina particles $(50 \%)$ prepared through gas pressure assisted infiltration (GPAI) was distributed during stirring. Distribution of the particles and structural characterization dependence on processing parameters were examined. Electron microscopy (SEM, TEM) was used for complex visual investigation of the distribution of dispersed particles and to quantify the degree of disintegration of the alumina master alloy after the casting process. To show the effect of the uniformity of the particle distribution on mechanical properties, uniaxial tests were performed after extrusion. Results show an increase in strength of the stir cast composites is in agreement with the particle distribution measurement (cluster size). The highest UTS values are achieved for composites with the lowest values of the remaining clusters.
\end{abstract}

$\mathrm{K}$ e y words: aluminum matrix composite, $\alpha-\mathrm{Al}_{2} \mathrm{O}_{3}$, alumina master alloy, stir casting, particle distribution

\section{Introduction}

Metal matrix composite materials consist of two or more physically and chemically distinct phases. Mostly, it is an engineered combination of metal and hard particle reinforcement to obtain tailored properties $[1,2]$. Various kinds of ceramic materials, e.g., $\mathrm{SiC}$, $\mathrm{Al}_{2} \mathrm{O}_{3}, \mathrm{MgO}$, and $\mathrm{B}_{4} \mathrm{C}$, are extensively used to reinforce aluminum alloy matrices. A wide range of manufacturing was developed to prepare particle-reinforced composite materials $[3-6]$.

As the most economical method, MMC prepared by stir casting technique is considered [7-9]. However, the wetting complexity of individual components is still the main disadvantage of this preparation technique. Improvement of wettability to a certain extent can be achieved by several methods including the addition of alloying elements (for example, magnesium, lithium, calcium, titanium, zirconium, silicon), preheating the particles to remove absorbed gases from the particle surface, or use of surface coatings [10-13]. The addition of alloying elements can modify the matrix metal alloy by producing a transient layer between the particles and the liquid matrix [14]. These interface-active elements should be chosen carefully, increasing the wettability and not disrupting the reinforcement particles function. Metallic coatings are used to improve the wettability of reinforcement within the matrix material and thereby cause a good bond between matrix alloy and reinforcement. A low-cost method for SiC particles by electroless nickel coating of the reinforcement can promote the wettability through increasing the overall surface energy of the reinforcement [15].

During the stir casting process, molten metal is stirred to form a vortex, and the reinforcement par-

*Corresponding author: e-mail address: nagy.stefan@savba.sk 
ticles are introduced mostly through the side of the vortex formed. The disadvantages of this method mainly arise from particle addition and stirring techniques. During particle addition, there is undoubtedly local solidification of the melt induced by the particles, which increases the viscosity of the slurry $[16,17]$. That is why one of the essential aspects of the casting process is the method of introducing the reinforcement phase (particles, fibers, whiskers) into the matrix melt. Several techniques have been described by Hashim et al., including master alloy pellets forming pre-infiltrated particles. These pellets are dispersed and diluted into a melt, followed by a slow hand or mechanical stirring [18]. Rasidhar et al. [19] prepared ilmenite nanocomposite by stir casting with $650-700$ RPM speed of stirring at a temperature of $850^{\circ} \mathrm{C}$ for $10-15 \mathrm{~min}$. Simultaneously, the reinforcement powder packed in aluminum foils was added to the melt as a packet. The particles were uniformly distributed in the aluminum matrix, but also, some clusters were formed, and the ultimate tensile strength increased with the wt.\% of ilmenite nanoparticles. Researchers also investigated the stirring blade properties to obtain the optimum performance of the stirring process. Impeller with blade angle $\left(\alpha=30^{\circ}\right)$ performed well and showed uniform dispersion without the concentration of particles. The position of the impeller should not be more than $30 \%$ of the height of the fluid from the base of the crucible to avoid the accumulation of reinforcement particles at the bottom of the crucible. In the research of Sahu et al. for the production of $\mathrm{Al} 7075 / \mathrm{B}_{4} \mathrm{C} / \mathrm{Fly}-$ -ash composite by stir casting, blade angle: $30^{\circ}$, impeller size: $0.5 \mathrm{D}$, and stirring speed: $550 \mathrm{RPM}$ is the suggested optimal condition for uniform distribution $[20]$.

Increased wettability was also reported with the solid-liquid mixed (SLiM) casting technique. In the SLiM casting process, the proportion of the added powder is up to $20-150 \mathrm{wt} . \%$; either the powder with the same composition as the molten matrix or the alien alloy but with good wettability is used as the added metal powder. The results by $\mathrm{Su}$ et al. [19-21] reveal that the poor dispersibility and low wettability of nanosized $\mathrm{Al}_{2} \mathrm{O}_{3}$ particles are improved via the carrier agent of $\mathrm{Al}$ powder.

In this study, gas pressure assisted infiltrated master alloy with a high content of reinforced particles $\left(\alpha-\mathrm{Al}_{2} \mathrm{O}_{3}\right)$ is used for introduction in stir casting to study the dissolution of alumina master alloy and distribution of the particles in the composite. The study aimed to investigate the effect of temperature, stirring speed, and stirring time on the distribution of particles, microstructure, and mechanical properties of the composite. Secondary processing, like extrusion of discontinuously reinforced composites, can lead to the break-up of particle agglomerates. Deformation of

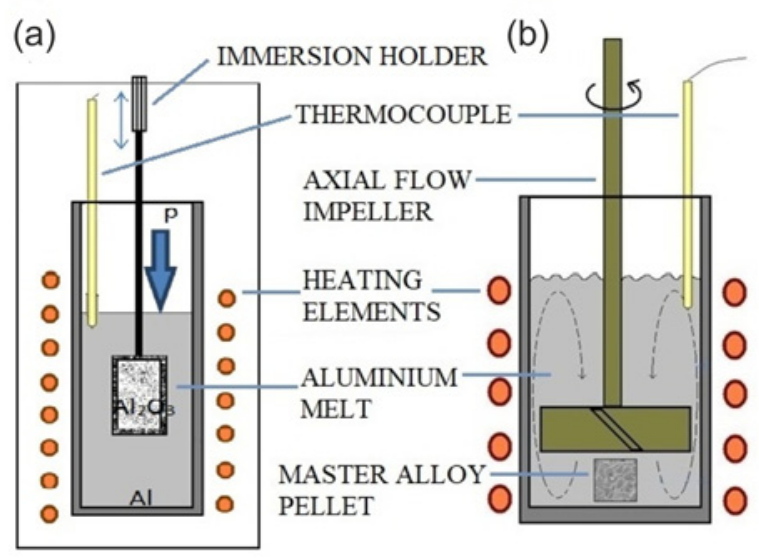

Fig. 1. Schematic illustration of GPAI (a) and stir casting process (b).

the material in the process of extrusion also reduced porosity [22-25].

\section{Experimental approach}

\subsection{Master alloy with alumina particles}

In the first step, the master alloy was prepared by infiltration loose ceramic particles with pure aluminum through gas pressure assisted infiltration technique, Fig. 1. Commercial alumina powder AMDRY 6060 with particle size (d50) $32.9 \mu \mathrm{m}$ and pure aluminum alloy 1050 were used in work. The master alloy contains $48 \pm 4$ vol.\% of $\mathrm{Al}_{2} \mathrm{O}_{3}$ reinforcement. The parameters of gas pressure infiltration were set to $850^{\circ} \mathrm{C}$ and $3 \mathrm{MPa}$ according to the previous study $[26,27]$. The loose $\mathrm{Al}_{2} \mathrm{O}_{3}$ was filled in a high porous graphite crucible, which was immersed in the $\mathrm{Al}$ melt after preheating to the adjusted temperature of infiltration. Subsequently, infiltration pressure was applied to penetrate the ceramic particles with molten aluminum. On cooling, infiltrated pellets were lifted out of the melt under applied pressure and were released after temperature decrease below the melting point of aluminum.

\subsection{Stir casting process}

The infiltrated master alloy was cut into $20 \mathrm{~g}$ piece pellets. To produce composite material with $5 \%$ of $\mathrm{Al}_{2} \mathrm{O}_{3}$ particles, the weight volume of pellet and pure aluminum 1050 was calculated. Graphite crucible with $\varnothing 45 \mathrm{~mm}(D)$ was used for heating the used materials. After reaching the preset temperature of aluminum in the crucible, the pellet was added into aluminum melt and further held on constant temperature for $60 \mathrm{~min}$. Afterward, the pellet was admixed and subse- 


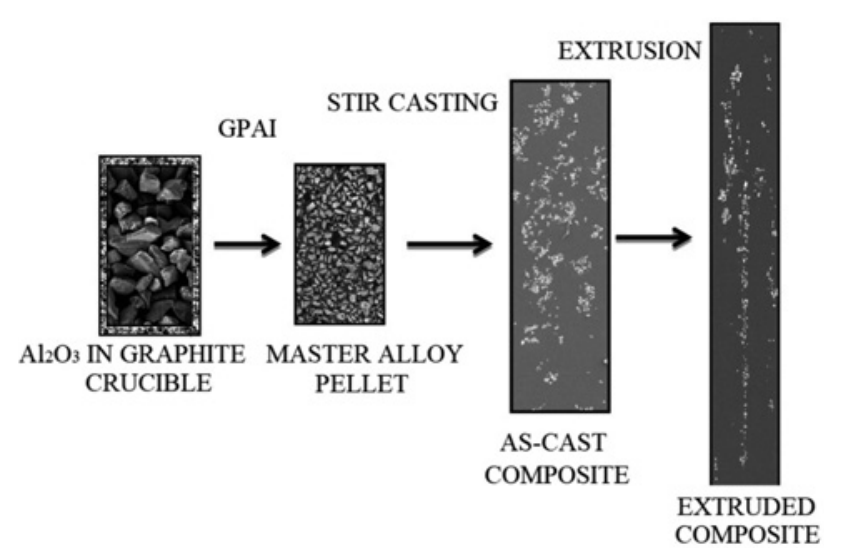

Fig. 2. Schematic illustration of the production process of the composite: 1 . step - preparation of master alloy with GPAI, 2. step - preheating and stir casting process, 3. step - extrusion.

quently disintegrated into the aluminum melt during the stir casting process, Figs. 1 and 2 (second step). An axial flow steel impeller was used to stir the molten metal under certain conditions. The steel impeller was coated with boron nitride. The depth of the impeller was set approximately $2 / 3$ the height of the molten metal from the bottom of the crucible, according to the study of Hashim et al. and Sahu et al. [17, 28]. Blade angle $30^{\circ}$ was chosen according to the impeller blade angle investigation by Sahu et al., which performed well and showed uniform dispersion [28]. The impeller diameter was $30 \mathrm{~mm}(0.6 D)$. The speed of the impeller was set to $600 \mathrm{RPM}(10 \mathrm{~Hz})$ and $1200 \mathrm{RPM}$ $(20 \mathrm{~Hz})$. The processing temperature was selected at 680,730 , and $780^{\circ} \mathrm{C}$. For a semi-solid casting temperature, $680^{\circ} \mathrm{C}$ was chosen. Different temperatures were selected in the range of standard casting temperatures for aluminum. The processing temperature also affects the preheating of the master alloy pellet and, subsequently, the dissolution process. The stirring time was 10 min for each melting temperature. For the temperature of $730^{\circ} \mathrm{C}, 30 \mathrm{~min}$ stirring time was also chosen to study the effect of the stirring time on the reinforcement particle distribution. Lower stirring time (10 min) may lead to the clustering of particle reinforcements and result in non-homogeneous distribution of reinforcement particles [28]. A cooper crucible with dimensions of $\varnothing 40 \times 120 \mathrm{~mm}^{2}$ was used to cast aluminum containing $\mathrm{Al}_{2} \mathrm{O}_{3}$ particles.

\subsection{Extrusion}

The composite samples were extruded into rod in the third step with a diameter of $6 \mathrm{~mm}$ with an area reduction ratio of 11 , which shows the schematic illustration in Fig. 2. The temperature of $425^{\circ} \mathrm{C}$ and the ram speed of $0.5 \mathrm{~mm} \mathrm{~s}^{-1}$ were set up.

\subsection{Methods of characterization}

To study the microstructure and the dispersion of the reinforcement particles in the matrix, SEM microscopes JEOL $7600 \mathrm{~F}$ and JEOL 6610 were used. The degree of distribution of particles was measured according to the remaining clusters of the disintegrated pellet in the as-cast composite. The diameter measurements of not dissolved clusters were done from SEM micrographs of the microstructure with the micrograph capturing software provided for the JEOL 6610 microscope. An example of measurement represents Fig. 5a. For each sample, at least 50 measurements were performed, and values were averaged.

Specimens for metallographic observation were prepared by grinding with 220, 400, 600, 800, 1200, and 2500 grit paper. Finally, the polishing was finished on cloth using diamond paste 10,3 , and $1 \mu \mathrm{m}$.

TEM was performed using JEOL TEM 1200EX microscope and FEI Titan HRSTEM to reveal the interface quality. Thin foils were prepared for the TEM studies using mechanical grinding and polishing, followed by ion milling with the GATAN PIPS II machine.

For tensile testing, samples with the gauge of $\varnothing 3 \times 30 \mathrm{~mm}^{2}$ were prepared and tested using a Zwick Roell 1474 testing machine with a test speed of $1.5 \mathrm{~mm} \mathrm{~min}^{-1}$ according to Standard Test Methods for Tension Testing ASTM E8. The mean values of the strength and elongation were calculated from four independent measurements.

\section{Results and discussion}

\subsection{Master alloy pellet characterization}

The microstructure of the master alloy contains a high concentration of $\alpha-\mathrm{Al}_{2} \mathrm{O}_{3}$ particles (48 $\pm 4 \mathrm{vol} . \%$ ), Fig. 3. The alumina particles are distributed in the space uniformly. The pressure infiltration process is essential to produce a proper interface between the particles and matrix and to exclude the gas phase from the alumina master alloy. The quality of the interface between aluminum and alumina is consistent and without reaction phases. However, infiltration pressure resulted in cracking of the particles, and micropores or uninfiltrated areas between cracks could also be seen, Fig. 3b. Non-infiltrated areas that contain a gas phase can decrease the wettability of the particles at the follow-up stir casting process.

\subsection{As-cast macrostructure and microstructure}

Macro- and microstructural observations were performed on the cross-section in the middle part of the 

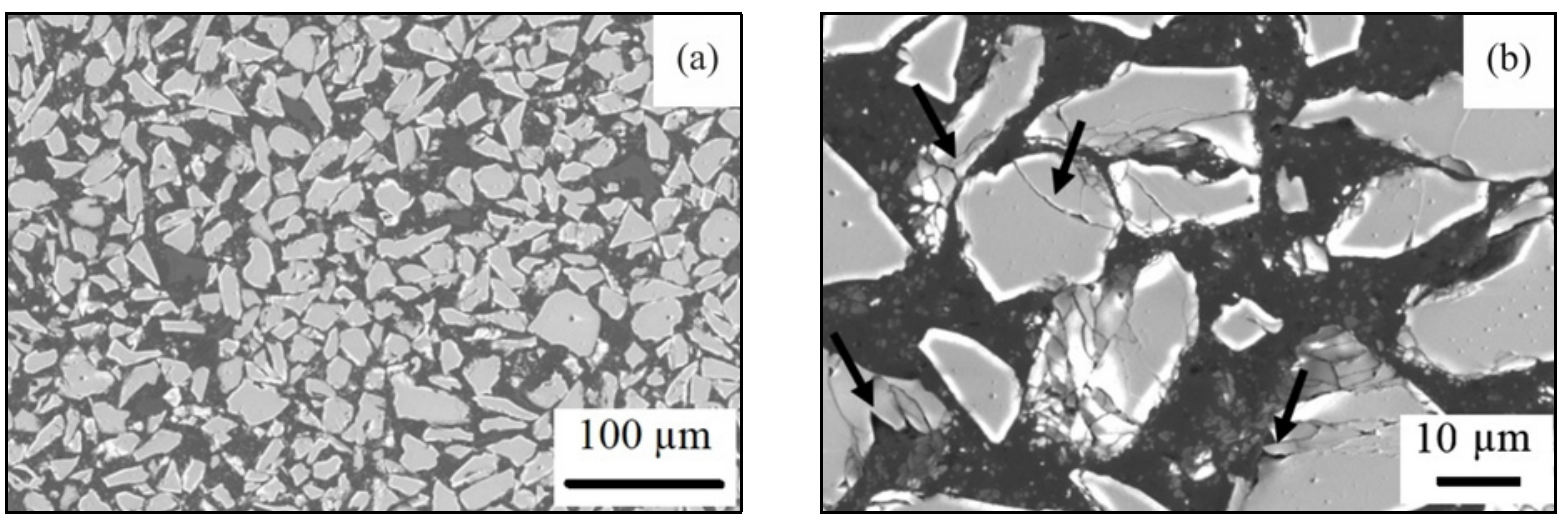

Fig. 3. The microstructure of alumina master alloy: (a) microstructure of $\mathrm{Al}_{2} \mathrm{O}_{3}$ particles in $\mathrm{Al}$ matrix (SEM) and (b) detail of the microstructure, cracked particles, and micropores indicated by arrows (SEM).

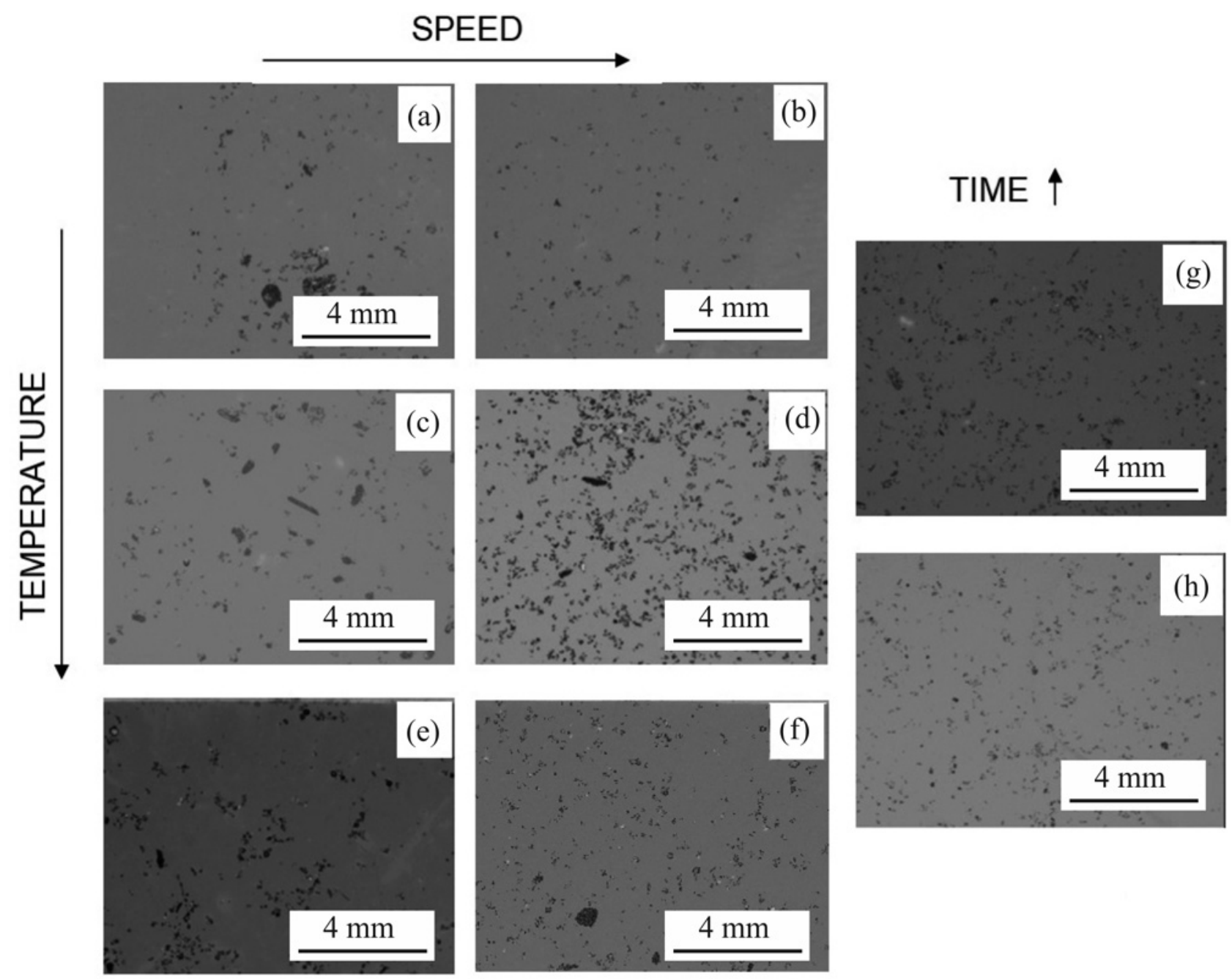

Fig. 4. Macrostructure of as-cast samples with casting parameters of: (a) $680^{\circ} \mathrm{C} / 600 \mathrm{RPM} / 10 \mathrm{~min}$, (b) $680{ }^{\circ} \mathrm{C} / 1200 \mathrm{RPM} /$ $10 \mathrm{~min}$, (c) $730^{\circ} \mathrm{C} / 600 \mathrm{RPM} / 10 \mathrm{~min}$, (d) $730^{\circ} \mathrm{C} / 1200 \mathrm{RPM} / 10 \mathrm{~min}$, (e) $780^{\circ} \mathrm{C} / 600 \mathrm{RPM} / 10 \mathrm{~min}$, (f) $780{ }^{\circ} \mathrm{C} / 1200 \mathrm{RPM} /$ $10 \mathrm{~min},(\mathrm{~g}) 730^{\circ} \mathrm{C} / 600 \mathrm{RPM} / 30 \mathrm{~min}$, and $(\mathrm{h}) 730^{\circ} \mathrm{C} / 1200 \mathrm{RPM} / 30 \mathrm{~min}$ (inverted SEM).

castings, depending on the stirring parameters (melt temperature, stirring speed, and stirring time). The as-cast samples indicate observable macro- and mi- crostructural differences of alumina master alloy disintegration and $\mathrm{Al}_{2} \mathrm{O}_{3}$ particles distribution, Fig. 4. The average remaining cluster size, the measurable 
Table 1. Mechanical properties of extruded composite and the average cluster size of composites

\begin{tabular}{lccccc}
\hline Sample & $\begin{array}{c}\text { Stir casting parameters } \\
\left({ }^{\circ} \mathrm{C}\right) /(\mathrm{RPM}) /(\min )\end{array}$ & $\begin{array}{c}\text { Average remaining/ } \\
\text { cluster size }(\mu \mathrm{m})\end{array}$ & $\begin{array}{c}\text { YS } \\
(\mathrm{MPa})\end{array}$ & $\begin{array}{c}\text { UTS } \\
(\mathrm{MPa})\end{array}$ & $\begin{array}{c}A \\
(\%)\end{array}$ \\
\hline Pure Al & - & - & $49.2 \pm 1$ & $72.7 \pm 3$ & $27 \pm 2$ \\
SC1 & $680 / 600 / 10$ & $368 \pm 38$ & $83.5 \pm 1.2$ & $107.7 \pm 7.5$ & $17 \pm 3$ \\
SC2 & $680 / 1200 / 10$ & $243 \pm 30$ & $83.4 \pm 1.3$ & $113 \pm 1.6$ & $12 \pm 5$ \\
SC3 & $730 / 600 / 10$ & $268 \pm 26$ & $71.9 \pm 1.5$ & $104 \pm 2$ & $18.6 \pm 1.3$ \\
SC4 & $730 / 1200 / 10$ & $193 \pm 27$ & $69.6 \pm 2.1$ & $104.3 \pm 1.3$ & $21 \pm 1.8$ \\
SC5 & $730 / 600 / 30$ & $136 \pm 24$ & $89.4 \pm 2.2$ & $131.8 \pm 1.1$ & $17.8 \pm 1.6$ \\
SC6 & $730 / 1200 / 30$ & $145 \pm 23$ & $100.4 \pm 5.1$ & $137.5 \pm 5.8$ & $12.8 \pm 1.5$ \\
SC7 & $780 / 600 / 10$ & $238 \pm 31$ & $83.3 \pm 2.7$ & $113.8 \pm 2.8$ & $12 \pm 2$ \\
SC8 & $780 / 1200 / 10$ & $179 \pm 36$ & $91.8 \pm 2.1$ & $121.7 \pm 10.3$ & $14 \pm 4$ \\
\hline
\end{tabular}
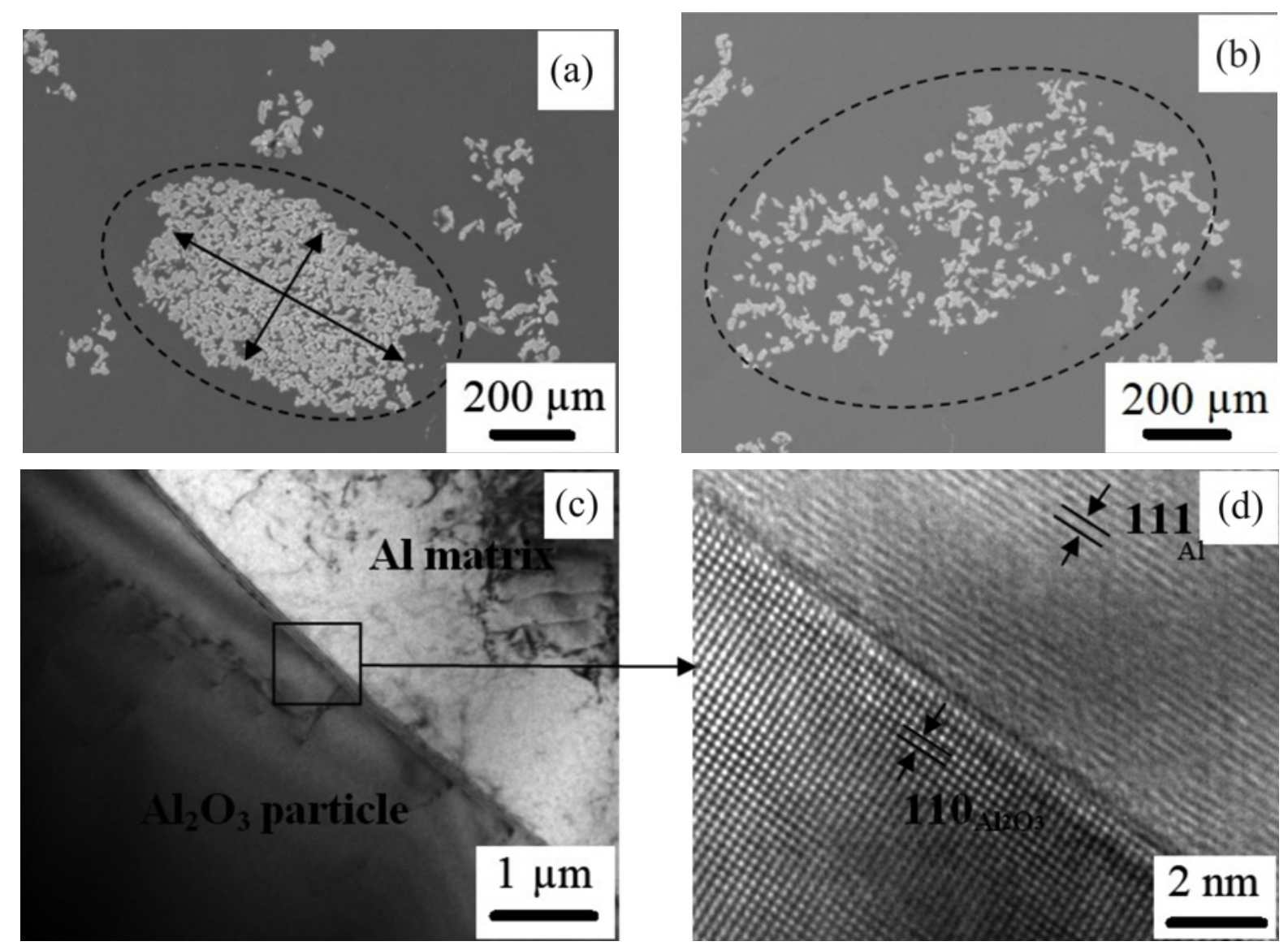

Fig. 5. Microstructure and interface of the as-cast sample: (a) cluster of $\mathrm{Al}_{2} \mathrm{O}_{3}$ particles (SEM), (b) disintegration stage of a cluster of $\mathrm{Al}_{2} \mathrm{O}_{3}$ particles (SEM), (c) interface between $\mathrm{Al}_{2} \mathrm{O}_{3}$ particle and $\mathrm{Al}$ matrix (TEM), and (d) atomic resolution interface between $\mathrm{Al}_{2} \mathrm{O}_{3}$ particle and $\mathrm{Al}$ matrix (HRTEM).

value of disintegration of master alloy on the chosen stir casting parameters, is represented in Table 1 and Fig. 6.

At a temperature of $680^{\circ} \mathrm{C}$ near the solidus, pure aluminum clusters of the alumina master alloy are clearly concentrated in the middle part of the cast sample SC1, Fig. 4a. An increase in stirring speed in the case of sample $\mathrm{SC} 2$ results in improved distribution of the alumina particles across the whole diameter of the casting. Also, the reduced remaining cluster size is measured, Fig. 3b.

In the case of the stirring temperature of $730^{\circ} \mathrm{C}$, the effects of both stirring speed and time were investigated. At stirring time $10 \mathrm{~min}$, the difference caused by increasing stirring speed is observable from the distribution of the $\mathrm{Al}_{2} \mathrm{O}_{3}$ particles. Large clusters are observed in sample SC3 with a stirring speed of 600 RPM, Fig. 4c. Increased stirring speed to 1200 RPM 


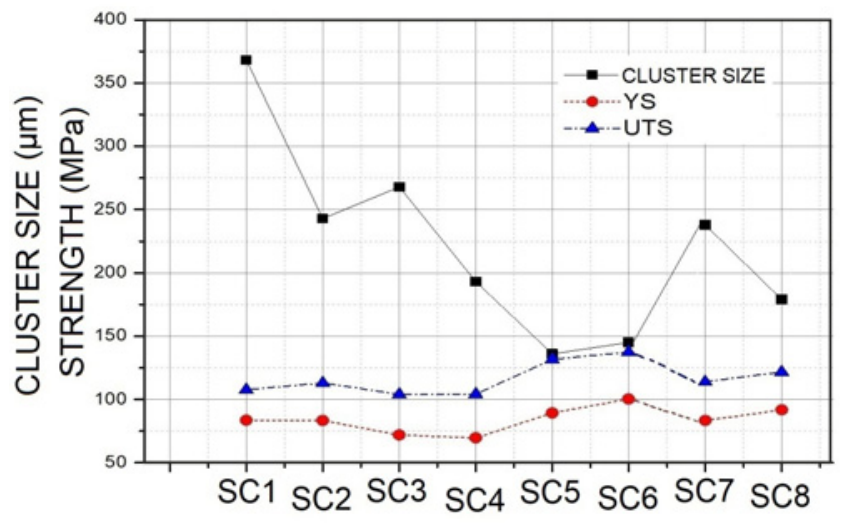

Fig. 6. Strength values of the tensile test according to the measured remaining cluster size.

reduces the cluster size, and the particles are distributed more homogeneously. In the case of stirring time $30 \mathrm{~min}$, enhanced disintegration and homogeneity of the $\mathrm{Al}_{2} \mathrm{O}_{3}$ particles are observed, but remaining clusters are still present, Figs. $4 \mathrm{~g}$,h. Increasing stirring speed from 600 to 1200 RPM slightly increases the remaining cluster size. Measurements of the remaining cluster sizes indicate the lowest values at the temperature of $730^{\circ} \mathrm{C}$. The boron nitride coating on the steel impeller was damaged after 30 min off stirring; however, there was no indication of boron nitride particles in the microstructure.

At the highest processing temperature of $780^{\circ} \mathrm{C}$, the $\mathrm{Al}_{2} \mathrm{O}_{3}$ particles are distributed through the whole volume of the casting, Figs 4e,f. Degree of the disintegration of the alumina master alloy after $10 \mathrm{~min}$ stirring time continued. The measured cluster size is lower compared to the values obtained at lower temperatures. A higher rate of stirring speed 1200 RPM has shown a decrease of cluster size, Fig. 6 .

A more thorough investigation on the microstructure level reveals a more extensive, not dissolved cluster of $\mathrm{Al}_{2} \mathrm{O}_{3}$ particles surrounded with smaller islands of $\mathrm{Al}_{2} \mathrm{O}_{3}$, Fig. 5a. The captured disintegration stage of one cluster in the stir casting process indicates the kinetics of disintegration, Fig. 5b. TEM observation reveals a clear and continuous interface of the $\mathrm{Al}_{2} \mathrm{O}_{3}$ particles and matrix, Fig. 5c. Further atomic resolution of the interface confirms the presence of $\alpha-\mathrm{Al}_{2} \mathrm{O}_{3}$, aluminum crystal structures according to interplanar spacing, and reveals tight interface without any interaction phase or microporosity of the interface, Fig. $5 \mathrm{~d}$.

\subsection{Mechanical properties}

A tensile test was realized to determine ultimate tensile strength (UTS), yield strength (YS), and ductility $(A)$ of prepared composite depending on stir casting conditions. To eliminate the residual poros-

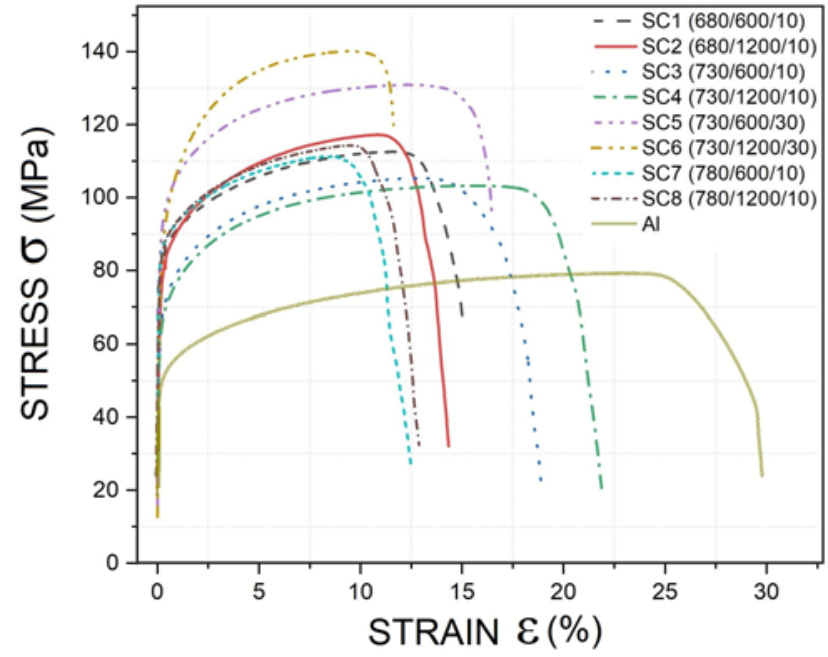

Fig. 7. Representative tensile stress-strain curves for tested samples.

ity after casting, the samples were directly extruded (see Fig. 2 for more details). Mechanical properties of extruded composites, pure aluminum, and the average remaining cluster size in the composites are summarized in Table 1. The strength values of the tensile test, according to the measured remaining cluster size of alumina master alloy for the prepared composites, are summarized in Fig. 6. The evaluation of the measured mechanical properties is in agreement with the measured remaining cluster size in the prepared composite. Decreasing the cluster size results in strength due to a more uniform distribution of the $\mathrm{Al}_{2} \mathrm{O}_{3}$ particles in the composite. Homogeneous dispersion of the particles results in a more uniform internal structure. The highest strength values are measured for the sample with the lowest cluster size prepared at temperature $730{ }^{\circ} \mathrm{C}$ with increased time of stirring to $30 \mathrm{~min}$.

Figure 7 shows representative stress-strain curves for the various manufacturing parameters, thus various homogeneity of reinforcement particles. The stress-strain curves have a standard shape with elastic and plastic regions without visible yield point. Variability in the ductility, YS, and UTS can be attributed mainly to the heterogeneity and size of the strengthening particles and their clusters. As mentioned by Roshan et al., during the tensile test of the reinforced samples, ceramic clusters exert constraints on the plastic flow with the ductile matrix [25]. Moreover, strengthening mechanism of the matrix during the loading also affects the shape of the curve, thus ductility, YS, and UTS values.

In the case of samples manufactured at 680 and $780^{\circ} \mathrm{C}$, the average mechanical properties are on similar levels. Slightly higher UTS was measured for the samples prepared on the temperature of $780^{\circ} \mathrm{C}$. The increased UTS is associated with the more homoge- 
neous distribution of the reinforced particles, thus enhanced dispersion hardening. This result also supports the fact that the remaining cluster size of $\mathrm{Al}_{2} \mathrm{O}_{3}$ particles on the temperature of $780^{\circ} \mathrm{C}$ is less than in the case of samples prepared at $680^{\circ} \mathrm{C}$. Preheating the master alloy pellet on a higher temperature of $780^{\circ} \mathrm{C}$ leads to higher heat absorption of the master alloy, which increases the dissolution. Increasing the speed of stirring in both cases lightly affected the UTS. The highest values of the remaining cluster size of $\mathrm{Al}_{2} \mathrm{O}_{3}$ particles are for the samples prepared at the temperature of $680^{\circ} \mathrm{C}$; however, as mentioned, the strength values are on the level of samples prepared at $780^{\circ} \mathrm{C}$. The increased strength values at near solidus temperature $680^{\circ} \mathrm{C}$ can be attributed to semi-solid casting strengthening. Semi-solid casting can increase mechanical properties due to refining the microstructure and decreasing the porosity [29]. The strain values are higher in this case. Using the temperature of $730^{\circ} \mathrm{C}$ and stirring time $10 \mathrm{~min}$ results in decreased UTS and YS values to the lowest level. The strain values are the highest at these parameters, and the distribution homogeneity is the same or increased against the samples prepared at $680^{\circ} \mathrm{C}$. Increasing the stirring time to 30 min results in the best distribution of homogeneity of the reinforcement particles in the microstructure producing the highest UTS and YS.

\section{Conclusions}

The presented work is focused on investigating the effect of the stir casting parameters on the microstructure and mechanical properties of the $\mathrm{Al} / \mathrm{Al}_{2} \mathrm{O}_{3}$ metal matrix composite produced using a new approach of alumina master alloy as a source reinforcement. The results of the study can be summarized as follows:

- It was shown that high volume fraction alumina master alloy $\left(\mathrm{Al} / \mathrm{Al}_{2} \mathrm{O}_{3}\right)$ could be used to introduce $\alpha-\mathrm{Al}_{2} \mathrm{O}_{3}$ particles into liquid aluminum during the dissolution in the stir casting process.

- Distribution homogeneity of the $\alpha-\mathrm{Al}_{2} \mathrm{O}_{3}$ particles strongly depends on stir casting parameters (temperature, stirring speed, stirring time).

- According to the cluster size measurements using SEM, parameters of $730{ }^{\circ} \mathrm{C} / 1200,600 \mathrm{RPM} / 30 \mathrm{~min}$ were the most efficient for disintegrating the master alloy pellet and homogeneous distribution of the $\mathrm{Al}_{2} \mathrm{O}_{3}$ reinforcement, what corresponds with the measured mechanical parameters.

- Increase in strength of the stir cast composites is in agreement with the particle distribution measurement (cluster size). The highest UTS values are achieved for composites with the lowest values of remaining clusters prepared with stir casting parameters $730^{\circ} \mathrm{C} / 1200,600 \mathrm{RPM} / 30 \mathrm{~min}$.

- The interface between the $\alpha-\mathrm{Al}_{2} \mathrm{O}_{3}$ particles and the $\mathrm{Al}$ matrix in the prepared composite is consistent without observable reaction products, confirming the TEM and HRTEM investigation.

\section{Acknowledgements}

This work was supported by the Slovak Foundation VEGA Grant 2/0135/19. Some results were acquired using infrastructure built during the projects ITMS 26240120006/ITMS 26240120020.

\section{References}

[1] J. F. Shackelford, Introduction to Materials Science for Engineering, 8. edition, Pearson, New Jersey, 2014. ISBN-13: 978-0133826654

[2] H. Ghandvar, M. H. Idris, N. Ahmad, N. Moslemi, Microstructure development, mechanical and tribological properties of a semi-solid A356/ $x \mathrm{SiCp}$ composite, Journal of Applied Research and Technology 15 (2017) 533-544. doi:10.1016/j.jart.2017.06.002

[3] K. D. Koli, G. Agnihotri, P. Rajesh, Properties and characterization of $\mathrm{Al}-\mathrm{Al}_{2} \mathrm{O}_{3}$ composites processed by casting and powder metallurgy routes (Review), International Journal of Latest Trends in Engineering and Technology 2 (2013) 486-497.

[4] S. M. Suresh, D. Mishra, A. Srinivasan, R. M. Arunachalam, R. Sasikumar, Production and characterization of micro and nano $\mathrm{Al}_{2} \mathrm{O}_{3}$ particle-reinforced LM25 aluminium alloy composites, ARPN Journal of Engineering and Applied Sciences 6 (2011) 94-98.

[5] R. G. Bhandare, P. M. Sonawane, Preparation of aluminium matrix composite by using stir casting method $\&$ its characterization, International Journal of Current Engineering and Technology 3 (2013) 148-155.

[6] A. Kumar, L. Shyam, S. Kumar, Fabrication and characterization of $\mathrm{A} 359 / \mathrm{Al}_{2} \mathrm{O}_{3}$ metal matrix composite using electromagnetic stir casting method, Journal of Materials Research and Technology 2 (2013) 250-254. doi:10.1016/j.jmrt.2013.03.015

[7] A. Ramanathan, K. K. Pradeep, M. Rajaraman, A review on the production of metal matrix composites through stir casting - Furnace design, properties, challenges, and research opportunities, Journal of Manufacturing Processes 42 (2019) 213-245. doi:10.1016/j.jmapro.2019.04.017

[8] S. Mathur, A. Barnawal, Effect of process parameter of stir casting on metal matrix composites, International Journal of Science and Research 2 (2013) 395-398.

[9] S. Pournaderi, S. Mahdavi, F. Akhlaghi, Fabrication of $\mathrm{Al} / \mathrm{Al}_{2} \mathrm{O}_{3}$ composites by in-situ powder metallurgy (IPM), Powder Technology 229 (2012) 276-284. doi:10.1016/j.powtec.2012.06.056

[10] V. Bharat, M. Nagaral, V. Auradi, Preparation of $6061 \mathrm{Al}-\mathrm{Al}_{2} \mathrm{O}_{3}$ metal matrix composite by stir casting and evaluation of mechanical properties, International Journal of Metallurgical \& Materials Science and Engineering 2 (2012) 22-31.

[11] H. Beyhi, H. R. Ezatpour, S. A. Sajjadi, S. M. Zebarjad, Microstructure evolution of $\mathrm{Al}-\mathrm{Al}_{2} \mathrm{O}_{3}$ micro and nano composites fabricated by a modified stir casting 
route, Proceedings of $18^{\text {th }}$ International Conference on Composite Materials, (2011), 59291170.

[12] R. K. Nayak, D. Rathore, B. C. Routara, B. Ch. Ray, Effect of nano $\mathrm{Al}_{2} \mathrm{O}_{3}$ fillers and cross head velocity on interlaminar shear strength of glass fiber reinforced polymer composite, International Journal of Plastics Technology 20 (2016) 334-344. doi:10.1007/s12588-016-9158-z

[13] S. Ren, X. Shen, X. Qu, X. He, Effect of Mg and Si on infiltration behavior of $\mathrm{Al}$ alloys pressureless infiltration into porous $\mathrm{SiCp}$ preforms, International Journal of Minerals, Metallurgy, and Materials 18 (2011) 703708. doi:10.1007/s12613-011-0500-3

[14] M. Mohammadpour, R. Azari Khosroshahi, R. Taherzadeh Mousavian, D. Brabazon, Effect of interfacialactive elements addition on the incorporation of micron-sized $\mathrm{SiC}$ particles in molten pure aluminum, Ceramics International 40 (2014) 8323-8332. doi:10.1016/j.ceramint.2014.01.038

[15] N. B. Khosroshahi, R. Azari Khosroshahi, R. Taherzadeh Mousavian, D. Brabazon, Effect of electroless coating parameters and ceramic particle size on fabrication of a uniform $\mathrm{Ni}-\mathrm{P}$ coating on $\mathrm{SiC}$ particles, Ceramics International 40 (2014) 12149-12159. doi:10.1016/j.ceramint.2014.04.055

[16] H. Nakae, S. Wu, Engulfment of $\mathrm{Al}_{2} \mathrm{O}_{3}$ particles during solidification of aluminum matrix composites, Material Science and Engineering A 252 (1998) 232238. doi:10.1016/S0921-5093(98)00664-9

[17] J. Hashim, L. Looney, M. S. J. Hashmi, Particle distribution in cast metal matrix composites - Part I, Journal of Materials Processing Technology 123 (2002) 251-257. doi:10.1016/S0924-0136(02)00098-5

[18] J. Hashim, L. Looney, M. S. J. Hashmi, Metal matrix composites: production by the stir casting method, Journal of Materials Processing Technology 92-93 (1999) 1-7. doi:10.1016/S0924-0136(99)00118-1

[19] L. Rasidhar, A. R. Krishna, Ch. S. Rao, Fabrication and investigation on properties of ilmenite $\left(\mathrm{FeTiO}_{3}\right)$ based $\mathrm{Al}$-nanocomposite by stir casting process, Int. J. Biosci. Biotechnol. 5 (2013) 193-200. doi: $10.1177 \% 2 \mathrm{~F} 0021998319876684$

[20] M. K. Sahu, R. K. Sahu, Optimization of stirring parameters using CFD simulations for HAMCs synthesis by stir casting process, Trans. Indian Inst. Met. 70 (2017) 2563-2570. doi:10.1007/s12666-017-1119-5

[21] H. Su, W. L. Gao, H. Zhang, H. B. Liu, J. Lu, Z. Lu, Study on preparation of large sized nanoparticle reinforced aluminium matrix composite by solid-liquid mixed casting process, Materials Science and Technology 28 (2012) 178-183. doi:10.1179/1743284711Y.0000000009
[22] S. Behnamfard, R. Taherzadeh Mousavian, R. A. Khosroshahi, D. Brabazon, A comparison between hot-rolling process and twin-screw rheo-extrusion process for fabrication of aluminum matrix nanocomposite, Materials Science and Engineering A 760 (2019) 152-157. doi:10.1016/j.msea.2019.05.109

[23] X. Ling, Y. Wenshu, Z. Qiqi, D. Ronghua, L. Xue, X. Ziyang, H. Murid, W. Gaohui, Effect of extrusion treatment on the microstructure and mechanical behavior of $\mathrm{SiC}$ nanowires reinforced $\mathrm{Al}$ matrix composites, Materials Science and Engineering A 682 (2017) 38-44. doi:10.1016/j.msea.2016.11.042

[24] R. T. Mousavian, R. A. Khosroshahi, S. Yazdani, D. Brabazon, Manufacturing of cast A356 matrix composite reinforced with nano- to micrometer-sized $\mathrm{SiC}$ particles, Rare Metals 36 (2017) 46-54. doi:10.1007/s12598-015-0689-9

[25] M. R. Roshan, R. T. Mousavian, H. Ebrahimkhani, A. Mosleh, Fabrication of Al-based composites reinforced with $\mathrm{Al}_{2} \mathrm{O}_{3}-\mathrm{TiB}_{2}$ ceramic composite particulates using vortex-casting method, Journal of Mining and Metallurgy 49 (2013) 299-305. doi:10.2298/JMMB120701032R

[26] S. Nagy, M. Nosko, L'. Orovčík, K. Iždinský, S. Kúdela Jr., P. Krížik, Pre-review study of the aluminum/alumina master alloy made through pressure infiltration, Materials and Design 66 (2015) 1-6. doi:10.1016/i.matdes.2014.09.035

[27] M. Nosko, S. Nagy, L. Weber, I. Mat́ko, M. Mihalkovič, K. Iždinský, L. Orovčík, Effect of Ca addition on interface formation in $\mathrm{Al}(\mathrm{Ca}) / \mathrm{Al}_{2} \mathrm{O}_{3}$ composites prepared by gas pressure assisted infiltration, Materials and Design 108 (2016) 618-623. doi:10.1016/j.matdes.2016.07.034

[28] M. K. Sahu, R. K. Sahu, Fabrication of aluminum matrix composites by stir casting technique and stirring process parameters optimization, Advanced Casting Technologies, chapter 7 (2018) 112-126. doi:10.5772/intechopen.73485

[29] G. T. Kridli, P. A. Friedman, J. M. Boileau, 7 - Manufacturing processes for light alloys, Materials, Design and Manufacturing for Lightweight Vehicles (2010) 235-274. doi:10.1533/9781845697822.2.235 